\title{
Auditory Working Memory Capacity in Congenitally Blind Children: Comparative Study with Normal
}

\author{
Nikita N*, Divya V and Krupa P \\ Mangalore University, India
}

Submission: February 11, 2021; Published: April 06, 2021

*Corresponding author: Nikita N, Assistant Professor, AJ Medical College of Speech and Hearing, Mangalore University, India

Keywords Auditory system; Compensatory hypothesis; Blind children; Short-term memory; Auditory attention; Visual cognitive systems; Crossmodal plasticity

\section{Introduction}

Studying blind individuals is an excellent opportunity to investigate how experience might shape auditory processing and how visual areas work even in the absence of visual stimuli. In everyday life, blind individuals rely more on auditory information than sighted humans to recognize people, localize events, or process language. A growing number of studies have provided evidence that the increased use of the auditory system results in compensatory behavior in the blind. This compensatory behavior in blinds predicted on the theory that the loss of visual information channel results in greater emphasis on the other sensory modalities. This implies increased requirements for auditory processing in blinds [1]. However, the use of auditory memory to process and information and the extent of superiority of auditory memory skill in blind is still being researched. Working memory plays an important role in carrying out our day-to-day activities. It is a system which is responsible for active maintenance, manipulation, and retrieval of task relevant information.

Conventional traditions found that blind individuals overcome few difficulties associated with their condition by developing unusual sensory and cognitive capacities [2]. In support to these traditions, recent studies have also found that congenital blind individuals perform superior to normal sighted individuals in various cognitive and perceptual skills like short term memory [3-6], long term memory [7], speech perception [1,8,9] and auditory frequency discrimination [10]. In contrast to these studies, there have been many studies have found no added advantage for blind individuals [11-16].
It is a well-known fact that the occipital lobe gets activated when processing visual stimuli in normal healthy sighted individuals. In blind individuals it has been found that it is active during verbal processing [17] and performance of memory tasks $[7,18]$. These results suggest that the advantages found in the behavioural tests may rely on cross-modal plasticity that enables visual areas to encode stimuli and tasks of other modalities in early blind individuals. Recent studies found that congenitally blind and early blind subjects perform better than late-blind subjects and normal on several auditory perception task [19-21]. These studies point to the plasticity of the sensory systems when an individual is confronted with the loss of a particular modality.

However, these studies do not inform us about the use and plasticity of the working memory system, but only about the interesting possibility of plasticity of one of the components, i.e., the visuospatial sketch pad that might be replaced by another sensory modality. Congenitally blind individuals have been shown to compensate for their loss of sight by developing extraordinary abilities in their remaining senses. An ongoing debate regarding whether blind individuals can compensate for their sensory handicap by developing exceptional abilities in their remaining senses (compensatory hypothesis), or by becoming severely handicapped (the deficit hypothesis) has yielded contrasting positions. Owing to such findings the present study was designed to assess the auditory memory abilities in congenitally blind children to throw a light on the research concerning the compensation for the loss of sight through other normal modality information and to comment on the plasticity of working memory system in blind. 


\section{Need of the study}

The existing research has paved way in understanding the extraordinary auditory perceptual skills in blind. Hence the need comes to investigate if the superior auditory perceptual skills lead to superior auditory memory too in blind. This would also enhance our understanding on cross-modal plasticity of sensory systems and their influence on cognitive system and on the plasticity of working memory system.

\section{Aim of the study}

To investigate auditory working memory capacity in congenitally blind children. To compare the auditory working memory capacity between congenitally blind children and normal sighted children.

\section{Method}

The present study aimed at assessing the auditory working memory capacity in congenitally blind children and compares them with the auditory working memory capacity of normal sighted children.

\section{Participants}

A total of 10 congenitally blind children and 10 normal sighted children participated in the study. There were 7 congenitally blind males and 2 females and 7 normal sighted males and 4 females in the age range of 15-17 years with the average age of 16.57 years. An informed consent was obtained from all the participants prior to conducting the study. All the subjects had hearing thresholds within $25 \mathrm{~dB}$ between frequencies $250 \mathrm{~Hz}$ to $8 \mathrm{KHz}$ in octaves in both the ears.

\section{Apparatus}

The following were used in one or more tasks: ASUS laptop, Sony digital recorder with external microphone and Stereo earphone.

\section{Procedure}

Auditory working memory was assessed in both the groups equally. It included,

\section{Working memory tasks}

Participants were assessed for standard auditory span measures consisting of digit forward task, digit backward task and letter-number sequencing task. Stimulus was created using MATLAB 2010a (Mathworks Inc., Natick, MA).

\section{Forward digit span}

In this task, the subjects were presented with lists of digits at progressively increasing numbers, beginning with a sequence of 3 digits. They were instructed to repeat the sequence aloud [in line with the method suggested by Kronenberger [22]]. With every correct response, the series increased in number by one step and after every incorrect response, series length was decreased by one step. The task was ended when the subject gave 4 consecutive incorrect responses. The longest sequence of digits that the subject correctly recalled was taken as the score obtained by the subject.

\section{Backward digit span}

This task is identical to digits forward except that, the series of digits had to be repeated in backward order Kronenberger [22].

\section{Letter-number sequencing}

Series of alphabets and numbers were presented in randomized order and the subjects were instructed to repeat alphabets first in alphabetical order and then numbers in numerical order at par with the method adopted by Mangalam [23]. The length of items presented increased by one step with every correct response and decreased by one step with every incorrect response. After 4 such trials, the task was terminated, and the last length of items repeated correctly was taken as the subject's score.

\section{Stroop task}

Alvin software was used for performing Stroop left-right task. Participants were presented with 40 stimuli using stereo earphones connected to ASUS laptop. The stimulus tokens were spoken by a male speaker. It included words 'left' and 'right' which were presented randomly in one of the ears. The participants were instructed to indicate in which ear the stimulus was heard, by raising ' $R$ '/'L' finger, following which the tester pressed ' $L$ ' on the keyboard if the word was heard in the left ear and ' $R$ ' if it was heard in the right ear irrespective of the word presented. The participants were asked to respond as quickly as possible. The reaction time was measured automatically by the software for each of the stimulus. The average reaction time was calculated for the total correct responses for each participant. Scores from all the above tasks were documented as the subject's score for the respective task.

\section{Results}

Results were analyzed using SPSS [16]. The study was conducted to compare the auditory working memory capacity between normal sighted and congenitally blind children. Three working memory tests were used namely, digit span test (digit forward and digit backward); letter-number sequencing and Stroop task. Mann Whitney U test was used to compare the performance between the two groups for all the tests. Results revealed that congenitally blind children had superior performance than the normal sighted children only in forward digit span test $(\mathrm{p}<0.05)$ and no significant difference between the two groups in other working memory tests $(p>0.05)$ and stroop test. It was also noted that though there was no significant difference obtained in tasks other than forward digit span, normal sighted children were found to have better scores compared to congenital blind children. Mean scores obtained for all the tests are shown in Figures 1-4. 


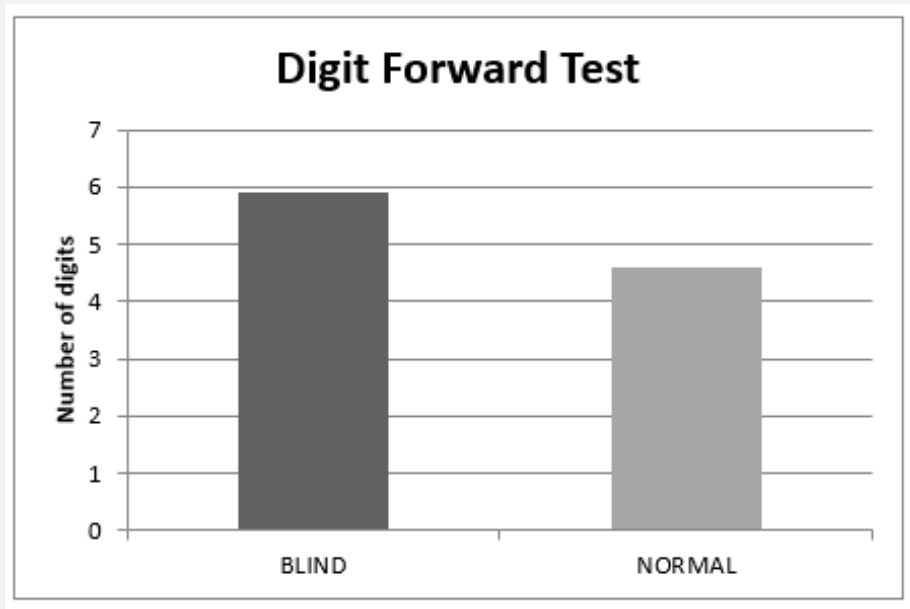

Figure 1: Bar graph showing mean for digit forward test scores for blind and normal sighted children.

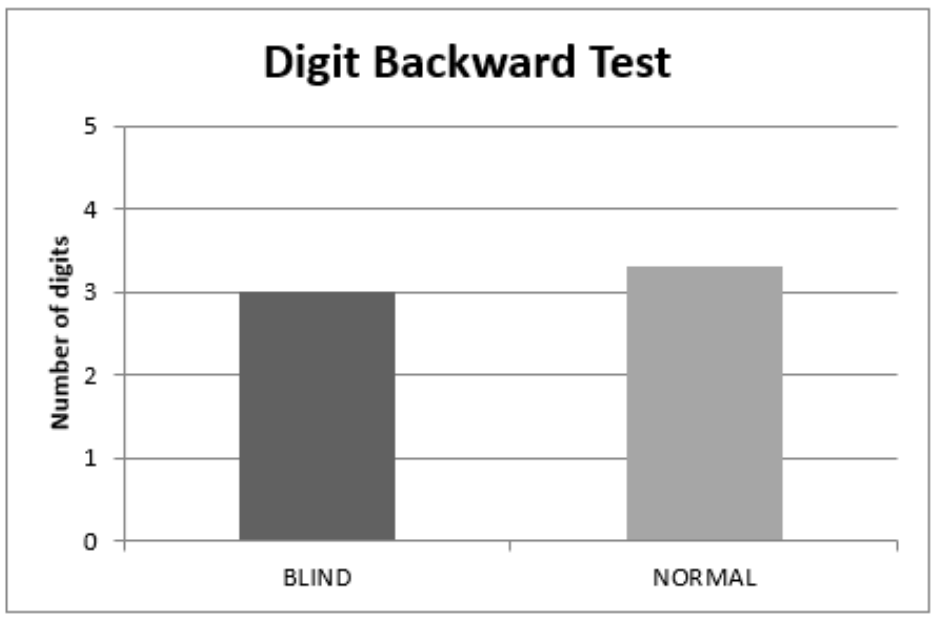

Figure 2: Bar graph showing mean for digit backward test scores for blind and normal sighted children.

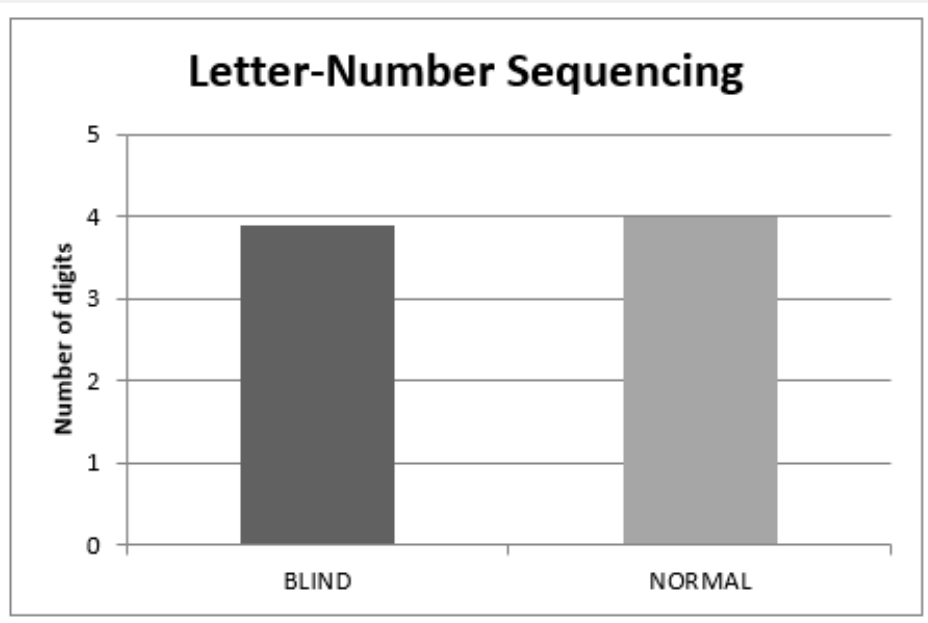

Figure 3: Bar graph showing mean for letter-number sequencing test scores for blind and normal sighted children. 


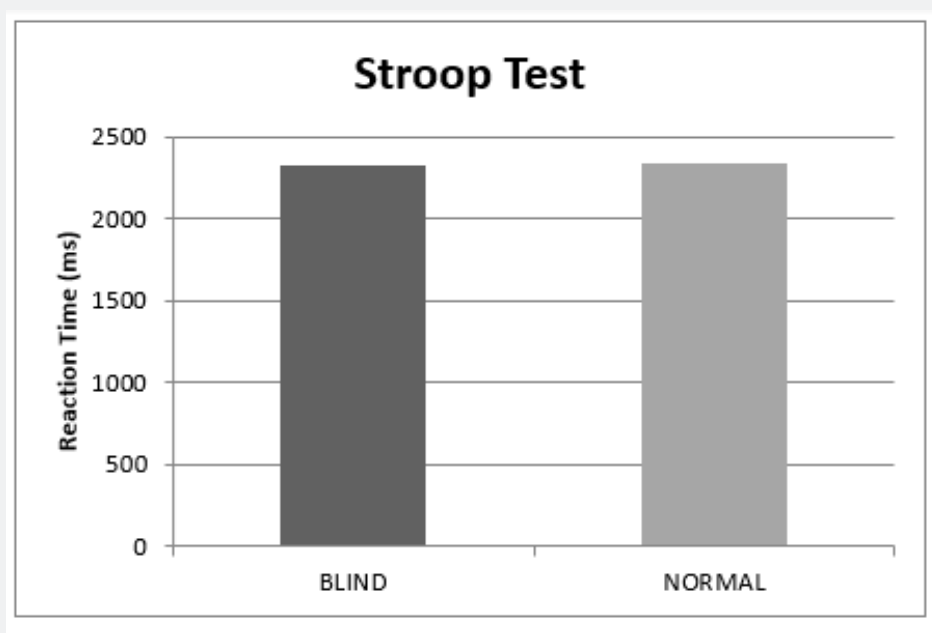

Figure 4: Bar graph showing mean for Stroop test scores for blind and normal sighted children.

\section{Discussion}

This study compared the performance of 10 congenially blind subjects and 10 individually matched sighted controls in four types of memory tasks: digit forward task, digit backward task, letter number task and stroop task. Continued use of working memory is essential for maintaining concentration, purposeful thinking, and mental effort during learning. In the absence of vision, perception of space is likely to be highly dependent on memory. Considering the folklore that have long maintained that blind individuals overcome their difficulties in visual modality by developing extraordinary sensory and cognitive capacity and the results of recent research showing a better auditory perceptual ability of the blind compared to normal, the present study aimed at investigating the auditory working memory capacity in congenitally blind children and compare their performance with the normal sighted children.

In this study we found that blind individuals possess a substantial advantage in memory tasks, when they are tested on serial recall task like forward digit span test. It was found that blind children had obtained significantly better scores in tasks involving direct repetition of digits serially (forward digit span), however when this task was modified into a memory manipulation task the advantage found in the serial recall task was lost. Support to this can be found in various other research that have found better short-term memory as well as serial recall memory in blind individuals compared to the normal sighted individuals [24]. We can assume that this may be because the blind constantly uses serial memory strategies in their everyday circumstances and hence develop superior serial memory skills that can also be used when required to recall a list of numbers as in the present study.

Lower performance in the manipulation tasks by blind individuals have been demonstrated in various other studies like Raz \& Mammarella Cornoldi [24,25]. These studies compared perfor- mance of visuospatial learning-disabled children (VSLD) and normal children in digit span and corti span tasks and found lower scores in backward digit span as well as backward corti span task in VSLD children compared to sighted children. They presumed that backward digit span task requires visuospatial resources which will be limited in VSLD children. Owing to such inference, our present finding can be supported by assuming that since congenital blind individuals have poor visuospatial skills, they could have had difficulty in performing manipulative tasks i.e., backward digit span task and letter-number sequencing task.

The interpretation on inferior backward digit span ability and letter-number sequencing ability is also consistent with previous findings, showing that blind individuals performed no better than sighted individuals when a memory task required manipulation or elaboration of the remembered items [12]. Studies by Vecchi [26] have also shown that congenitally blind individuals were more severely hampered by the requirement to actively manipulate the testing items in working memory when performing a memory task. Thus, it can be concluded that the memory advantages in the blind may stem from their ability to chunk together consecutively presented items, but this advantage disappears when they need to manipulate and recall the presented items. Blind individuals are found to have better auditory attention [15]. The confounding results seen in our study may be due to procedural variations.

Overall findings indicate that though congenitally blind individuals have improved auditory perceptual ability and serial recall ability they may not be superior to normal sighted children in manipulative and recall memory tasks.

\section{Summary and Conclusion}

The present study was designed to investigate the auditory working memory in congenitally blind children. The study was carried out using four tasks namely, forward digit span, backward 
digit span, letter-number sequencing and stroop. We found that except for forward digit span task, blind children scored lower than normal sighted children in all other memory tasks. The results can be attributed to superior short-term memory and serial recall ability in blind and limited visuospatial resources needed to perform manipulative tasks (backward digit span and letter-number sequencing). An important outcome of this research might be to train educators to realize the potential of focused activities and to encourage them to plan strategies to incorporate such activities in their daily work with visually impaired children. It would be of interest to further study whether blind individuals possess other better executive functions and if they have an impact on their auditory perceptual ability and on the crossmodal plasticity of auditory and visual cognitive systems.

\section{References}

1. Starlinger I, Niemeyer W (1981) Do the blind hear better? Investigations on auditory processing in congenital or early acquired blindness. II. Central functions. Audiology 20: 510-515.

2. Wagner Lampl A, Oliver G W (1994) Folklore of blindness. J Vis Impair Blin 88: 267-276.

3. Hull T, Mason H (1995) Performance of blind children on digit span tests. J Vis Impair Blin 89(2): 166-169.

4. Juurma J (1967) Ability structure and loss of vision. Research Series 18.

5. Smits B W G M, Mommers M J C (1976) Differences between blind and sighted children on WISC verbal subtests. New Outlook 70(6): 240246.

6. Tillman H M, Bashaw W L (1968) Multivariate analysis of the WISC scales for blind and sighted children. Psychol Rep 23(2): 523-526.

7. Amedi A, Raz N, Pianka P, Malach R, Zohary E (2003) Early 'visual' cortex activation correlates with superior verbal memory performance in the blind. Nat Neurosci 6 (7): 758-766.

8. Hugdahl K, Ek M, Takio F, Rintee T, Tuomainen J, et al. (2004) Blind individuals show enhanced perceptual and attentional sensitivity for identification of speech sounds. Brain Res Cogn Brain Res 19(1): 2832.

9. Muchnik C, Efrati M, Nemeth E, Malin M, Hildesheimer M (1991) Central audi-tory skills in blind and sighted subjects. Scand Audiol 20(1): 19-23.

10. Gougoux F, Lepore F, Lassonde M, Voss P, Zatorre R J (2004) G Neuropsychology: Pitch discrimination in the early blind. Nature 430(6997): 309.
11. Agrawal R, Singh M P (1988) Primacy and recency effects among the blind. Psychol Resea 32: 26-30.

12. Bliss I, Kujala T, Hamalainen H (2004) Comparison of blind and sighted par-ticipants' performance in a letter recognition working memory task. Cognitive Brain Research 18: 273-277.

13. Morrongiello B A, Timney B, Humphrey G K, Anderson S, Skory C (1995) Spatial knowledge in blind and sighted children. J Exp Child Psychol 59: 211-233.

14. Sholl M J, Easton R D (1986) Effect of referent object familiarity on verbal learning in the sighted and the blind. J Exp Psychol Learn Mem Cogn 12(2): 190-200.

15. Liotti M, Ryder K, Woldroff M G (1998) Auditory attention in the congenitally blind: where, when and what gets recognized. Neuroreport 9(6): 1007-1012.

16. Wyver S R, Markham R (1998) Do children with visual impairment demonstrate superior short-term memory, memory strategies and metamemory? Journal of Visual Impairment and Blindness 92: 799811.

17. Roder B, Stock O, Bien S, Neville H J, Rosler F (2002) Speech processing activates visual cortex in congenitally blind humans. Eur J Neurosci 16: 930-936.

18. Burton H (2003) Visual cortex activity in early and late blind people. J Neurosci 23(10): 4005-4011.

19. Roder B, Rosler F (2003) Memory for environmental sounds in sighted, congenitally blind and late blind adults: Evidence for cross-modal compensation. Int J Psychophysiol 50: 27-39.

20. Stevens A A, Weaver K (2005) Auditory perceptual consolidation in early onset blindness. Neuropsychologia 43: 1901-1910.

21. Wan C Y, Wood A G, Reutens D C, Wilson S J (2010) Early but not late blindness leads to enhanced auditory perception. Neuropsychologia 48(1): 344-348.

22. Kronenberger W G, Pisoni D B, Henning S C, Colson B G, Hazzard L M H (2010) Working memory training for children with cochlear implants: A pilot study. J Speech Lang Hear Res 10: 01-19.

23. Mangalam M K, Ram D, Praharaj S K, Sarkhel S (2010) Working memory in schizophrenia. Germ J Psyc 13(3): 116-120.

24. Raz N, Striem E, Pundak G, Orlov T, Zohary E (2007) Superior serial memory in the blind: A case of cognitive compensatory adjustment. Current Biology 17(13): 1129-1133.

25. Raz N, Amedi A, Zohary E (2005) V1 activation in congenitally blind humans is associated with episodic retrieval. Cerebral Cortex 15(9): 1459-1468.

26. Vecchi T (1998) Visuo-spatial imagery in congenitally totally blind people. Memory 6 (1): 91-102. 
(C) This work is licensed under Creative (C) Commons Attribution 4.0 License BY DOI: 10.19080/GJO.2021.24.556133
Your next submission with Juniper Publishers will reach you the below assets

- Quality Editorial service

- Swift Peer Review

- Reprints availability

- E-prints Service

- Manuscript Podcast for convenient understanding

- Global attainment for your research

- Manuscript accessibility in different formats ( Pdf, E-pub, Full Text, Audio)

- Unceasing customer service

Track the below URL for one-step submission https://juniperpublishers.com/online-submission.php 